\title{
Efficacy of Korean Red Ginseng in the Treatment of Alopecia Areata
}

\author{
Ga Na Oh and Sang Wook Son* \\ Department of Dermatology, Korea University College of Medicine, Seoul 136-705, Korea
}

\begin{abstract}
Alopecia areata (AA) is an autoimmune disease that can affect any hair-bearing area. AA is known to be caused by immunological disorder but still, the pathogenesis is not fully understood. Many therapeutic modalities have been used to treat alopecia areata, with variable efficacy and safety profiles. Unfortunately, none of these agents is definitely curative or preventive alone. We studied hair growth efficacy and safety of Korean red ginseng (KRG) in AA comparing corticosteroid intra-lesional injection (ILI) alone patient group with ILI with KRG taking patient group using Folliscope 2.5 for $12 \mathrm{wk}$. Herein, we would like to report the efficacy of KRG in the treatment of AA and recommend KRG as a useful complimentary food for gaining efficacy of treatment for AA.
\end{abstract}

Keywords: Panax ginseng, Alopecia areata, Corticosteroid

\section{INTRODUCTION}

Alopecia areata (AA) is a common, non-scarring, autoimmune disease that can affect any hair-bearing area. The disease can present as a single, well-demarcated patch of hair loss, multiple patches, or extensive hair loss. It is known to be caused by association with autoimmunity, but the pathogenesis is still uncertain. The prevalence in the general population is $0.1 \%$ to $0.2 \%$ [1]. The life-time risk of developing AA is estimated by $1.7 \%$ [2]. The disease course of AA is unpredictable. About half of patients will convalesce within 1 year, even without treatment [3]. However, most patients will experience more than one episode of hair loss. As a result, these patients can suffer from depression and anxiety [4]. Various therapeutic modalities, including localized or systemic corticosteroids, minoxidil, topical immunotherapy, phototherapy and systemic therapy have been used to treat AA, with variable efficacy and safety profiles. Unfortunately, none of these agents is definitely curative or preventive alone. The most commonly used modality is intra-lesional injection (ILI) of corticosteroids. However, this method is ac-

(c) This is an Open Access article distributed under the terms of the Creative Commons Attribution Non-Commercial License (http://creativecommons.org/licenses/by-nc/3.0/) which permits unrestricted non-commercial use, distribution, and reproduction in any medium, provided the original work is properly cited. companied by pain in most patients, and the application of ILI in extensive AA or longstanding AA is limited. Also, there are no reports of definite therapies using oral agents, including food, for patients with AA.

In Korea, many home-remedies are used for hair loss, and Korean red ginseng (KRG) is well known to effective for prevention of hair loss and growth of hair. However, there are still no reports of the efficacy of KRG in AA using medical engineering techniques. Thus, the authors studied hair growth efficacy and safety of KRG in AA, comparing a patient group who underwent corticosteroid ILI alone to a patient group who underwent ILI while taking KRG.

\section{MATERIALS AND METHODS}

\section{Study design}

Following the criteria for diagnosis of Korean AA patients, 50 patients diagnosed with AA were enrolled. They were divided into two groups (each with 25 pa-

Received 02 Apr. 2012, Revised 07 Aug. 2012, Accepted 14 Aug. 2012

*Corresponding author

E-mail: skin4u@korea.ac.kr

Tel: +82-2-920-6433, Fax: +82-2-928-7540 
tients): group 1 was treated with corticosteroid ILI while taking KRG, and group 2 was treated with corticosteroid ILI alone. Scalp photography and phototricogram (Folliscope 2.5; LeadM Co., Seoul, Korea) were done at baseline $(0 \mathrm{wk})$ and $12 \mathrm{wk}$. The study protocol was approved by the institutional review board (IRB) of the Korea University Ansan Hospital (IRB no. AS 10035). Informed consent was obtained from all study participants.

\section{Inclusion criteria}

The inclusion criteria during this study were as follows: A) patients who had been diagnosed with AA more than 2 wk prior; B) patients who needed treatment; C) patients who received an explanation of the objective, methods, and efficacy of this clinical trial and who agreed to participate in the study; and D) patients over 15 years of age.

\section{Exclusion criteria}

The exclusion criteria during this study were as follows: A) patients who had been treated with other products or medication within $2 \mathrm{wk}$ before initiation into this clinical study; B) patients who were allergic to a component of KRG; C) patients receiving medication for another disease; D) patients who were pregnant or breastfeeding; E) patients who had been enrolled in another clinical study within $3 \mathrm{mo}$; F) patients who were not able to understand the objectives and methods of this clinical trial; and G) other patients considered by the clinician to be inappropriate for participation in this clinical study.

\section{Measurement}

Phototrichogram

First, hair measurement was done using a computerized hand-held USB camera phototricogram (Folliscope $2.5)$ at baseline $(0 \mathrm{wk})$ and $12 \mathrm{wk}$. The leading site of the bald scalp was assessed with tattooing. The hair density (number of hairs per square centimeter) and hair thickness (micrometer) were measured. Hair density per square centimeter was conducted manually under 50-fold magnification. Hair thickness was measured under 100fold magnification.

\section{Expert panel assessment of global photographs}

Standardized global photographs of the leading site of the bald scalp were obtained at baseline ( 0 wk) and 12 wk. The patient's head was placed in a stereotactic device to maintain consistency of patient positioning and photographic distance [5]. Subjects were trained to maintain the same hair style and to avoid dyeing their hair or using any hair enhancement procedures throughout the study.
Global photographs were reviewed in a blinded manner by an expert panel of three dermatologists at the end of the trial using a 4-point scale. Assessments included percentage of scalp affected by AA and an assessment of hair regrowth using the 4-point scale. The 4-point scale measures hair regrowth as follows: 1 indicates 'no recovery' that includes deterioration as well as no change; 2 , 'poor recovery,' only vellus hairs are observed; 3 , 'partial recovery,' generally terminal regrowth is observed, however, under $60 \%$ of regrowth; and 4 , 'marked recovery,' cosmetically satisfied status or over $60 \%$ of regrowth on the lesion.

\section{Statistical analysis}

Student $t$-tests used to examine whether there were any statistically significant differences between two groups.. All of the statistical analysis was done by SPSS ver. 12.00 (SPSS Inc., Chicago, IL, USA) program. A $p$-value under 0.05 was considered to be a significant result.

\section{RESULT}

\section{Characterization of patients}

The patient group included a total of 50 patients, $22 \mathrm{fe}-$ male patients and 28 male patients. Patients' ages ranged from 22 to 52 years old, and the mean age of group 1 was 35.7 years and that of group 2 was 38.5 years (Table 1). There were 36 patients who had only one lesion and 5 patients who had over three lesions. The average number of lesions was 1.48 .

\section{Hair density}

The average hair number of group 1 was $44.27 / \mathrm{cm}^{2}$ at baseline. After treatment with corticosteroid ILI and $\mathrm{KRG}$, it increased to $101.39 / \mathrm{cm}^{2}$ at $12 \mathrm{wk}$. In group 2, the hair density also increased from $40.21 / \mathrm{cm}^{2}$ to $91.17 /$ $\mathrm{cm}^{2}$. The hair density of group 1 increased relatively more than group 2. However, there were no statistically significant differences between these data in the two groups $(p>0.05)$ (Table 2).

Table 1. Age and sex distribution of alopecia areata patients

\begin{tabular}{lcc}
\hline & $\begin{array}{c}\text { Group 1 } \\
\text { (corticosteroid ILI + KRG) }\end{array}$ & $\begin{array}{c}\text { Group 2 } \\
\text { (corticosteroid ILI alone) }\end{array}$ \\
\hline Age (yr) & $35.7 \pm 14$ & $38.5 \pm 13$ \\
$\begin{array}{l}\text { Gender } \\
\text { (male/female) }\end{array}$ & $13 / 12$ & $15 / 10$ \\
\hline
\end{tabular}

The patient group included a total of 50 patients, 22 female patients and 28 male patients.

ILI, intra-lesional injection; KRG, Korean red ginseng. 
Table 2. Hair density at baseline and 12 wk after treatment (number/ $\mathrm{cm}^{2}$ )

\begin{tabular}{ccc}
\hline & Baseline & $12 \mathrm{wk}$ \\
\hline Group 1 & $44.27 \pm 3.68$ & $101.39 \pm 4.14$ \\
(corticosteroid ILI + KRG) & & \\
Group 2 & $40.21 \pm 3.18$ & $91.17 \pm 2.97$ \\
(corticosteroid ILI alone) & & \\
\hline
\end{tabular}

The hair density of group 1 increased relatively more than group 2 . However, there were no statistically significant differences between these data in the two groups $(p>0.05)$.

ILI, intra-lesional injection; KRG, Korean red ginseng.

Table 3. Hair thickness at baseline and $12 \mathrm{wk}$ after treatment $(\mathrm{mm})$

\begin{tabular}{ccc}
\hline & Baseline & $12 \mathrm{wk}$ \\
\hline $\begin{array}{c}\text { Group 1 } \\
\text { (corticosteroid ILI + KRG) }\end{array}$ & $0.062 \pm 0.003$ & $0.085 \pm 0.002$ \\
Group 2 & $0.058 \pm 0.004$ & $0.078 \pm 0.007$ \\
(corticosteroid ILI alone) & & \\
\hline
\end{tabular}

In both of two groups, the hair thickness increased after treatment. However, there were no statistically significant differences between these data in the two groups $(p>0.05)$.

ILI, intra-lesional injection; KRG, Korean red ginseng.

Table 4. Expert panel assessment of global photographs (4-point scale)

\begin{tabular}{ccc}
\hline & $\begin{array}{c}\text { Group 1 } \\
\text { (corticosteroid ILI + KRG) }\end{array}$ & $\begin{array}{c}\text { Group 2 } \\
\text { (corticosteroid ILI alone) }\end{array}$ \\
\hline Score & $3.6 \pm 0.6^{1)}$ & $3.1 \pm 0.5$ \\
\hline
\end{tabular}

ILI, intra-lesional injection; KRG, Korean red ginseng.

${ }^{1)}$ Significant difference compared to control group $(p=0.047)$.

\section{Hair thickness}

The average hair thickness in group 1 was $0.062 \mathrm{~mm}$, and it increased to $0.085 \mathrm{~mm}$ after $12 \mathrm{wk}$ of combination therapy. In group 2, the hair thickness also increased from $0.058 \mathrm{~mm}$ to $0.078 \mathrm{~mm}$. However, there were no statistically significant differences between these data in the two groups $(p>0.05)$ (Table 3).

\section{Expert panel assessment of global photographs}

Global photographs were reviewed in a blinded manner by an expert panel of three dermatologists at the end of the trial using a 4-point scale. The average score of group 1 was 3.6 and that of group 2 was 3.1. There were statistically significant differences between these data in the two groups $(p<0.05)$ (Table 4$)$.

\section{Safety assessment}

In this study, no specific side-effect, such as gastrointestinal trouble, skin rashes, etc., were observed in the KRG medicated patient group.

\section{DISCUSSION}

AA is an autoimmune disease that presents as nonscarring hair loss. AA can occur on virtually any hair-bearing area, but it affects the scalp in approximately $90 \%$ of cases [6]. The hair loss can present as single limited patches of hair loss (most common), multiple patches, or extensive hair loss. The disease is frequently asymptomatic, although a few patients report pruritus, burning sensations, or pain before hair loss begins [7]. Trichotillomania and tinea capitis are the most important differential diagnoses, especially in children. Diffuse AA can be easily misdiagnosed as telogen effluvium or lupus, and secondary syphilis may also be considered in the differential diagnosis of AA [8]. The most important factors indicating a poor prognosis are the extent of hair loss presentation [9]. Other factors associated with a poor prognosis include a long duration of hair loss [10], atopy, a positive family history, the presence of other autoimmune diseases, nail involvement, and young age of first onset [7]. The pathogenesis of AA and the molecular mechanisms that lead to hair loss are poorly understood. Recent research studies have indicated that AA is an inflammation-driven disease and is likely an autoimmune disorder [11-13]. The presence of inflammatory lymphocytes around and within affected hair follicles and the ability to promote hair regrowth with the use of immunosuppressive agents is consistent with an autoimmune hypothesis [14].

The Cochrane review has shown that few therapies for AA have been comprehensively evaluated in randomized controlled trials, and it concluded that there were no validated treatments for AA [15]. A lack of good evidencebased data for therapeutic approaches is a challenge to the dermatologist in choosing efficacious AA treatments. Several studies have shown the efficacy of intralesional corticosteroid injections. Abell and Munro [16] reported hair regrowth in $71 \%$ of patients with subtotal AA treated by triamcinolone acetonide injections and in $7 \%$ of a placebo group. For limited scalp AA, intralesional corticosteroid therapy is considered to be the drug of choice by many experts. The most widely used agent is triamcinolone acetonide. Side effects include transient atrophy and telangectasia.

$\mathrm{KRG}$ is a popular herbal medicine used worldwide for a broad range of indications, including diabetes, cardiovascular disease, chronic liver disease, and atopic dermatitis [17-20]. Many researchers believe that KRG has potential as a therapeutic modality for treatment of many dermatologic diseases. Our previous study showed that KRG may be helpful in treatment of androgenic alopecia 
[21]. However, there are no studies about the correlation between AA and KRG. Kim et al. [22] reported a potent effect on the recovery of hair follicles by KRG through its combined effects on proliferation and apoptosis of cells in the hair follicle in mouse animal models. These hair growth-promoting effects are associated with components of KRG such as ginsenoside-Rb1 and 20(S)-ginsenoside-Rg3 [23]. Ginsenosides are the major components of KRG, and its anti-allergic and anti-inflammatory effects have already been identified [24]. We think that these anti-inflammatory effects might be linked to the ability to promote hair regrowth. Also, this endorses the above-mentioned autoimmune hypothesis. However, as this is a clinical study, we suppose that further basic studies of the mechanism of KRG in AA may be required.

In particular, at the 12th week after initiation, the result of expert panel assessment of global photographs showed statistically significant improvement. The hair density and hair thickness, measured by Folliscope 2.5, also showed a tendency of some improvement.

In summary, these results suggest that treatment with KRG can result in improved hair regrowth in AA patients. We demonstrated that KRG may be a helpful functional food for use in management of AA patients.

\section{ACKLOWLEDGEMENTS}

This work was supported by the 2010 grant from the Korean Society of Ginseng funded by the Korea Ginseng Corporation.

\section{REFERENCES}

1. Safavi K. Prevalence of alopecia areata in the First National Health and Nutrition Examination Survey. Arch Dermatol 1992;128:702.

2. Safavi KH, Muller SA, Suman VJ, Moshell AN, Melton LJ 3rd. Incidence of alopecia areata in Olmsted County, Minnesota, 1975 through 1989. Mayo Clin Proc 1995;70:628-633.

3. Shapiro J, Madani S. Alopecia areata: diagnosis and management. Int J Dermatol 1999;38 Suppl 1:19-24.

4. Gupta MA, Gupta AK, Watteel GN. Stress and alopecia areata: a psychodermatologic study. Acta Derm Venereol 1997;77:296-298.

5. Canfield D. Photographic documentation of hair growth in androgenetic alopecia. Dermatol Clin 1996;14:713721.

6. Wasserman D, Guzman-Sanchez DA, Scott K, McMichael A. Alopecia areata. Int J Dermatol 2007;46:121-
131.

7. Madani S, Shapiro J. Alopecia areata update. J Am Acad Dermatol 2000;42:549-566.

8. Alkhalifah A, Alsantali A, Wang E, McElwee KJ, Shapiro J. Alopecia areata update. Part I. Clinical picture, histopathology, and pathogenesis. J Am Acad Dermatol 2010;62:177-188.

9. Tosti A, Bellavista S, Iorizzo M. Alopecia areata: a long term follow-up study of 191 patients. J Am Acad Dermatol 2006;55:438-441.

10. Lew BL, Shin MK, Sim WY. Acute diffuse and total alopecia: a new subtype of alopecia areata with a favorable prognosis. J Am Acad Dermatol 2009;60:85-93.

11. Lu W, Shapiro J, Yu M, Barekatain A, Lo B, Finner A, McElwee K. Alopecia areata: pathogenesis and potential for therapy. Expert Rev Mol Med 2006;8:1-19.

12. McDonagh AJ, Tazi-Ahnini R. Epidemiology and genetics of alopecia areata. Clin Exp Dermatol 2002;27:405409.

13. Paus R, Slominski A, Czarnetzki BM. Is alopecia areata an autoimmune-response against melanogenesis-related proteins, exposed by abnormal MHC class I expression in the anagen hair bulb? Yale J Biol Med 1993;66:541-554.

14. McElwee KJ, Tobin DJ, Bystryn JC, King LE Jr, Sundberg JP. Alopecia areata: an autoimmune disease? Exp Dermatol 1999;8:371-379.

15. Delamere FM, Sladden MM, Dobbins HM, Leonardi-Bee J. Interventions for alopecia areata. Cochrane Database Syst Rev 2008;(2):CD004413.

16. Abell E, Munro DD. Intralesional treatment of alopecia areata with triamcinolone acetonide by jet injector. Br J Dermatol 1973;88:55-59.

17. Ernst E. Panax ginseng: an overview of the clinical evidence. J Ginseng Res 2010;34:259-263.

18. Vuksan V, Sievenpipper J, Jovanovski E, Jenkins AL. Current clinical evidence for Korean red ginseng in management of diabetes and vascular disease: a Toronto's Ginseng Clinical Testing Program. J Ginseng Res 2010;34:264-273.

19. Abdel-Wahhab MA, Gamil K, El-Kady AA, El-Nekeety AA, Naguib KM. Therapeutic effects of Korean red ginseng extract in Egyptian patients with chronic liver diseases. J Ginseng Res 2011;35:69-79.

20. Lee KG, Son SW. Efficacy of Korean red ginseng in the treatment of atopic dermatitis. J Ginseng Res 2011;35: 149-154.

21. Kim JH, Yi SM, Choi JE, Son SW. Study of the efficacy of Korean red ginseng in the treatment of androgenic alopecia. J Ginseng Res 2009;33:223-228.

22. Kim SH, Jeong KS, Ryu SY, Kim TH. Panax ginseng 
prevents apoptosis in hair follicles and accelerates recovery of hair medullary cells in irradiated mice. In Vivo 1998;12:219-222.

23. Matsuda H, Yamazaki M, Asanuma Y, Kubo M. Promotion of hair growth by ginseng radix on cultured mouse vibrissal hair follicles. Phytother Res 2003;17:797-800.

24. Park EK, Choo MK, Han MJ, Kim DH. Ginsenoside Rh1 possesses antiallergic and anti-inflammatory activities. Int Arch Allergy Immunol 2004;133:113-120. 